\title{
Preparation of Zeolite Y Using Local Raw Material Rice Husk as a Silica Source
}

\author{
M. M. Rahman ${ }^{\mathrm{a} 1}$, N. Hasnida ${ }^{\mathrm{b}}$, and W. B. Wan Nik

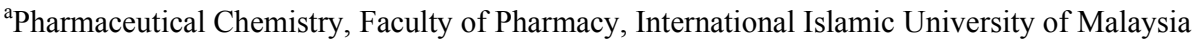 \\ (IIUM), 5200 Kuantan, Pahang, Malaysia \\ ${ }^{\mathrm{b}}$ Maritime Technology Department, Faculty of Maritime Studies and Marine Science, Universiti \\ Malaysia Terrenganu (UMT, Mengabang Telipot, 21030 Kuala Terengganu, Malaysia
}

Received 11 December 2008, accepted in final revised form 5 February 2009

\begin{abstract}
The locally available rice husk is found to provide a good alternative source of highly active silica for the synthesis of zeolites. The present synthesis of zeolite Y using seed and feed gel method yields maximum crystallinity and rich in zeolite $Y$ and which shows the absence of other impurities. This compared with preparation of zeolite Y seeding and without seeding methods using commercial silica which yields a mixture of zeolite Y and P.

Keywods: Rice husk; Zeolite Y; Seeding method; Ageing method; Highly active silica.

(C) 2009 JSR Publications. ISSN: 2070-0237 (Print); 2070-0245 (Online). All rights reserved.

DOI: $10.3329 /$ jsr.v1i2.1777
\end{abstract}

\section{Introduction}

Zeolites are crystalline aluminosilicates with fully cross-linked open framework structures made up of corner-sharing $\mathrm{SiO}_{4}$ and $\mathrm{AlO}_{4}$ tetrahedra. The first zeolite, called stilbite, was discovered by Cronstedt in 1756 [1] who found that the mineral loses water rapidly on heating and thus seems to boil. The name "zeolite" comes from the Greek words zeo (to boil) and lithos (stone). A representative empirical formula of a zeolite is

$$
\mathrm{M}_{2 / \mathrm{n}} \mathrm{O} \cdot \mathrm{Al}_{2} \mathrm{O}_{3} \cdot x \mathrm{SiO}_{2} \cdot \mathrm{yH}_{2} \mathrm{O} \rightarrow
$$

where $\mathrm{M}$ represents the exchangeable cation of valence $\mathrm{n}$. $\mathrm{M}$ is generally a Group I or II ion, although other metal, non-metal and organic cations may also balance the negative charge created by the presence of $\mathrm{Al}$ in the structure. The framework may contain cages and channels of discrete size, which are normally occupied by water [2]. Most researchers in their definition of a zeolite now include "virtually all types of porous oxide structures that have well-defined pore structures due to a high degree of crystallinity." The classical

\footnotetext{
${ }^{1}$ Corresponding author: mokhles63@hotmail.com
} 
definition of a zeolite is a crystalline, porous aluminosilicate. However, some recent discoveries of materials virtually identical to the classical zeolite, but consisting of oxide structures with elements other than silicon and aluminum have stretched the definition.

Faujasite (FAU) zeolite Y: Zeolite Y exhibits the FAU (faujasite) structure. It has a 3-dimensional pore structure with pores running perpendicular to each other in the $\mathrm{x}, \mathrm{y}$, and $\mathrm{z}$ planes similar to Linde Type A (LTA), and is made of secondary building units 4, 6 , and 6-6. The pore diameter is large at $7.4 \AA$ since the aperture is defined by a 12 member oxygen ring, and leads into a larger cavity of diameter $12 \AA$. The cavity is surrounded by ten sodalite cages (truncated octahedra) connected on their hexagonal faces. The unit cell is cubic $(a=24.7 \AA)$ with $F d-3 m$ symmetry. Zeolite $\mathrm{Y}$ has a void volume fraction of 0.48 , with a $\mathrm{Si} / \mathrm{Al}$ ratio of 2.43 . It thermally decomposes at $793^{\circ} \mathrm{C}[3-5]$.

One of the main constituents in zeolite is silica, $\mathrm{SiO}_{3}$. Commercial silica (sand) is variable in reactivity and selectivity. The annual production of rice in Malaysia is 2.2 million metric ton. Rice husk disposal is one of the current major problems in Malaysia. Market studies indicate that Malaysia has abundant supply of rice husk which is more than 100000 metric ton per annum excluding the amount accumulated over the years. Disposal by rotting and open burning is hazardous to the environment and health. Silica is the major constituent of rice husk. Silica ash which is obtained from the complete burning of the husk constitutes $15-20 \%$ of the total weight of the rice husk. The silica ash produced contains more than $90 \% \mathrm{SiO}_{2}$. Rice husk can therefore provide a good alternative source of highly active silica for the synthesis of zeolite. In the present study amorphous silica from rice husk ash has been used as the silica source in the synthesis of zeolite Y.

\section{Methodology}

\subsection{Preparation of rice husk ash (RHA)}

The rice husk was treated with $10 \%$ sulfuric acid $\left(\mathrm{H}_{2} \mathrm{SO}_{4}\right)$ for 24 hours for preliminary removing all impurities. The treated rice husk was washed thoroughly with distilled water, dried at $100{ }^{\circ} \mathrm{C}$ and pyrolyzed in oxygen atmosphere at $500{ }^{\circ} \mathrm{C}$ for 6 hours. The residual ash with about $99 \%$ w/w silica was dissolved in $\mathrm{NaOH}$ solution to obtain a desired composition of sodium silicate solution.

\subsection{Preparation seed gel}

$$
\text { 10.67 } \mathrm{Na}_{2} \mathrm{O}: 1 \mathrm{Al}_{2} \mathrm{O}_{3}: 10 \mathrm{SiO}_{2}: 180 \mathrm{H}_{2} \mathrm{O}
$$

A $500 \mathrm{~mL}$ Teflon beaker containing a magnetic stirrer was washed with deionized water. Sodium hydroxide $(1.6616 \mathrm{~g})$ was added slowly to deionzed water and stir until clear and homogenous solution appeared for about 5 minutes. The aqueous solution of sodium hydroxide was ready for the preparation of seed gel. Two milliliter aqueous solution of sodium hydroxide was added to $0.7515 \mathrm{~g}$ sodium aluminate oxide until a homogenous mixture was formed; silica oxide or rice husk ash $1.5361 \mathrm{~g}$ was added separately to $5.5 \mathrm{~mL}$ sodium hydroxide aqueous until homogenously mixed. Both of the preparations were 
heated under vigorous stirring to obtain a homogenous mixture. The sample was aged for 24 hours at room temperature in the Teflon bottle. The flow chart of the process is shown in Fig. 1. The aluminate and silicate solutions were mixed together in the Teflon beaker, subsequently stirred for $2 \mathrm{hrs}$ with the purpose of making it completely homogenized. This combined solution was used as the feed stock gel.

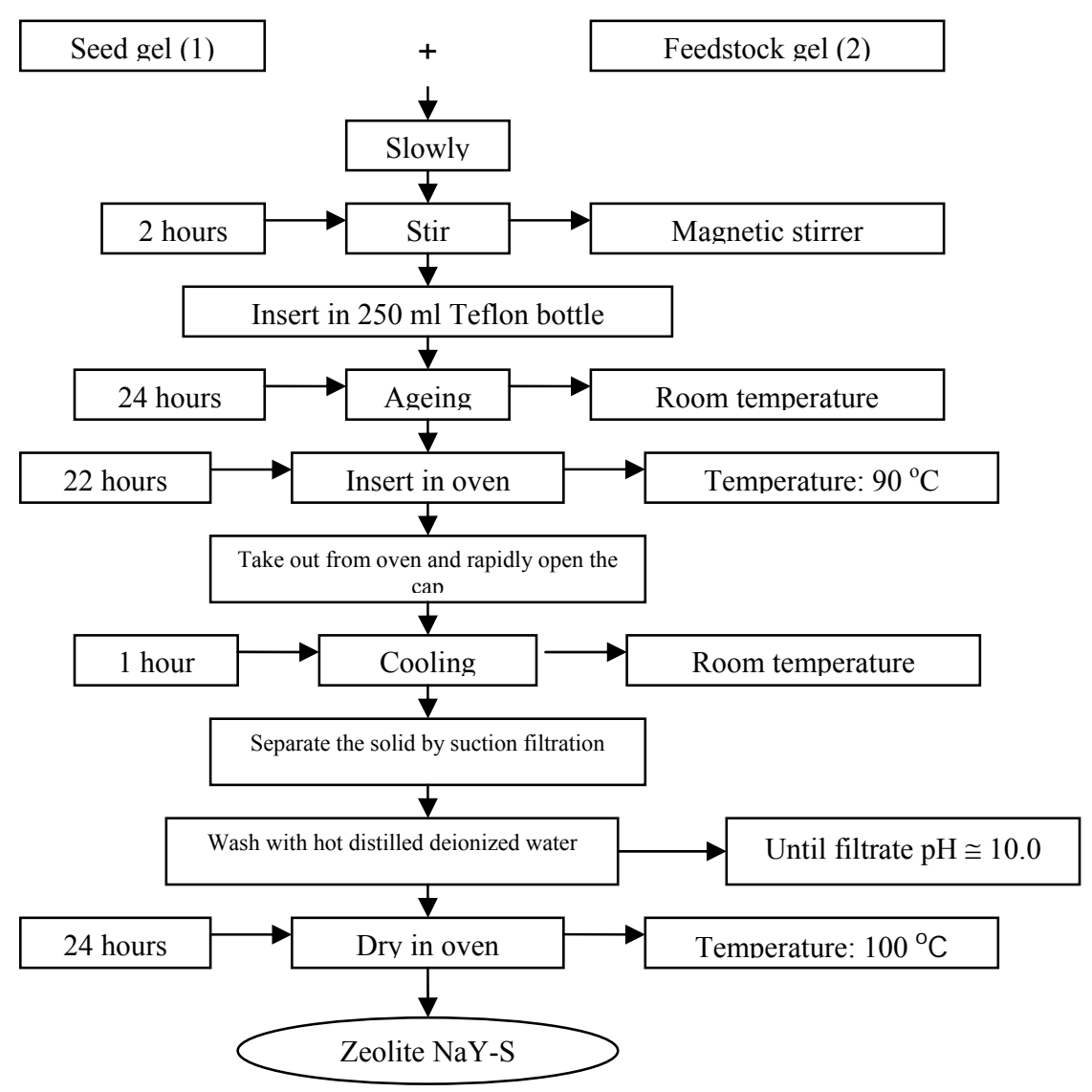

Fig. 1. Flow Chart of zeolite Y preparation.

\section{Result and Discussion}

\subsection{Characterization of RHA}

The RHA produced from rice husk through pretreatment with $10 \% \mathrm{H}_{2} \mathrm{SO}_{4}$ is highly amorphous and it has low impurities and better yield. The observed yield (Table 1) of RHA from acid wash is $16.0 \%(\mathrm{w} / \mathrm{w})$ and without acid wash is $13.0 \%(\mathrm{w} / \mathrm{w})$. Structural characterization of the rice husk ash by FTIR and XRD shows that the ashes consist 
mainly of silica in the amorphous phases. Elemental analysis RHA with acid wash indicates that it contained $95.85 \% \mathrm{SiO}_{2}$, other compounds are present in trace amounts such as carbon, $\mathrm{K}_{2} \mathrm{O}$, and $\mathrm{CaO}$. Meanwhile the elemental analysis of RHA without acid wash shows that only $90 \% \mathrm{SiO}_{2}$. Quantification of the acid wash RHA by EDAX shows in the Table 1 that their impurities are negligible. Consequently, rice husk ash was suitable for synthesis of zeolite as it contain high percentage of amorphous silica form. From this point of view, the objective to recycle waste material and produce a valuable product and the production of high quality silica oxide was achieved according to the EDAX analysis.

Table 1. Elemental analysis of rice husk ash (acid wash and without acid wash).

\begin{tabular}{ccccccc}
\hline & $\mathrm{C}(\%)$ & $\mathrm{O}(\%)$ & $\begin{array}{c}\mathrm{SiO}_{2} \\
(\%)\end{array}$ & $\mathrm{K}_{2} \mathrm{O}$ & $\mathrm{CaO}$ & $\begin{array}{c}\text { Yield \% of } \\
\text { ash (w/w) }\end{array}$ \\
\hline Acid wash & 4.04 & 51.07 & 44.81 & 0.04 & 0.04 & 16 \\
$\begin{array}{c}\text { Without acid } \\
\text { wash }\end{array}$ & 8.68 & 48.25 & 42.08 & 0.44 & 0.54 & 13 \\
\hline
\end{tabular}

\subsection{Characterization of zeolite $Y$ by FTIR, XRD and SEM}

The product was characterized by Fourier Transform Infra Red (FTIR) and X-ray Diffractometer (XRD) to confirm the formation of zeolite $\mathrm{Y}$. Washed colloidal suspensions of crystals were dried overnight in polystyrene boats at $100^{\circ} \mathrm{C}$ and then ground into a powder form for powder XRD and FTIR. Vibrational spectroscopy of zeolite show strong IR absorption in the spectral region below $1200 \mathrm{~cm}^{-1}$. Vibration frequencies of the zeolite lattice, which results from stretching and bending modes of the T-O units which is observed in the range 300 to $1300 \mathrm{~cm}^{-1}$ indicates that $\mathrm{SiO}_{4}$ or $\mathrm{A}_{10}$ are linked.

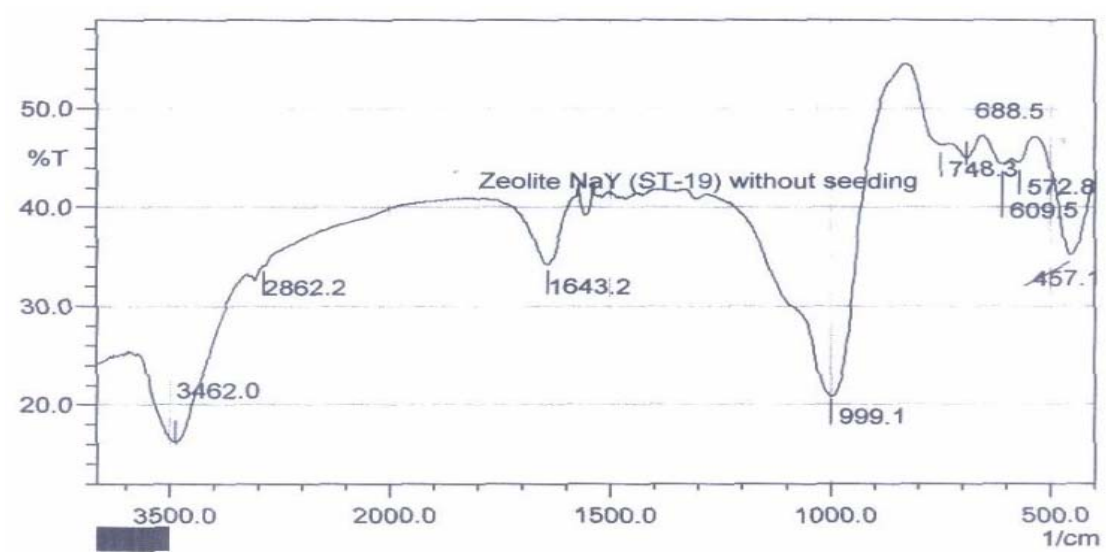

Fig. 2. IR spectra of zeolite $Y$ without seeding. 
Powder XRD (Siemens D-500 diffractometer using $\mathrm{Cu} K \alpha$ radiation) was used to determine sample crystallinity. The formation of zeolite $\mathrm{Y}$ phase was confirmed by comparing the diffractograms of all synthesized samples to the diffractogram of the reference zeolite Y. IR spectra of zeolite $\mathrm{Y}$ without seeding, with seeding and commercial zeolite $\mathrm{Y}$ are shown in Fig. 2 and Fig. 3, respectively. From these figures, an IR spectrum of zeolite $\mathrm{Y}$ with seeding is similar to that of the commercial zeolite $\mathrm{Y}$.

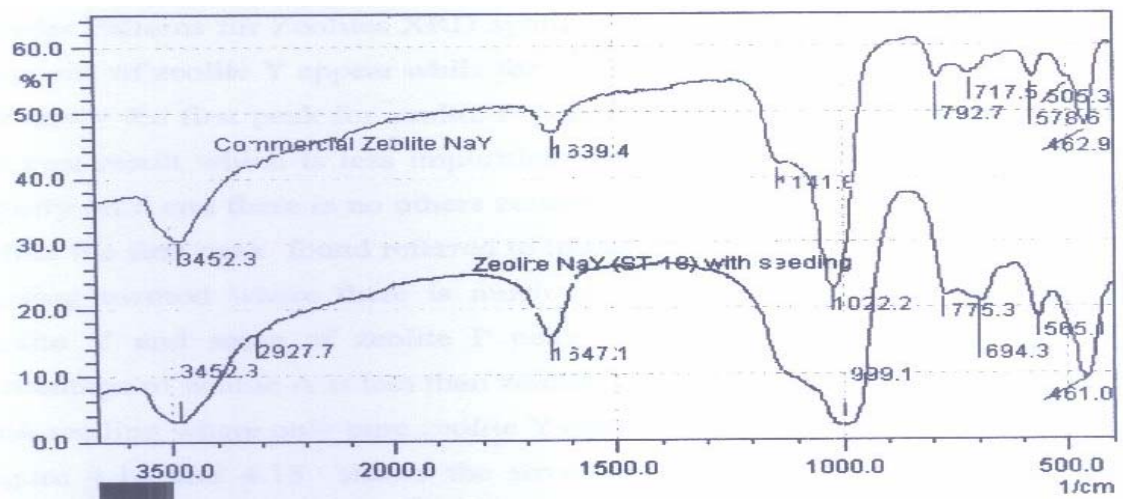

Fig. 3. IR Spectra of commercial zeolite Y and with seeding zeolite.

According to Treacy and Higgins [6], the XRD first peak will appear in the range $(2 \theta=$ $\left.2-50^{0}\right) 6-10^{0}$ for the zeolite $\mathrm{Y}$, for zeolite A the first peak will appear around $7-10^{\circ}$ and for zeolite $\mathrm{P}$ the first peak will appear after $10^{\circ}$. The prepared zeolite $\mathrm{Y}$ without seeding (Fig. 4) was found to have a mixture of zeolites $Y, A$ and P. The small zig-zag peak refers to

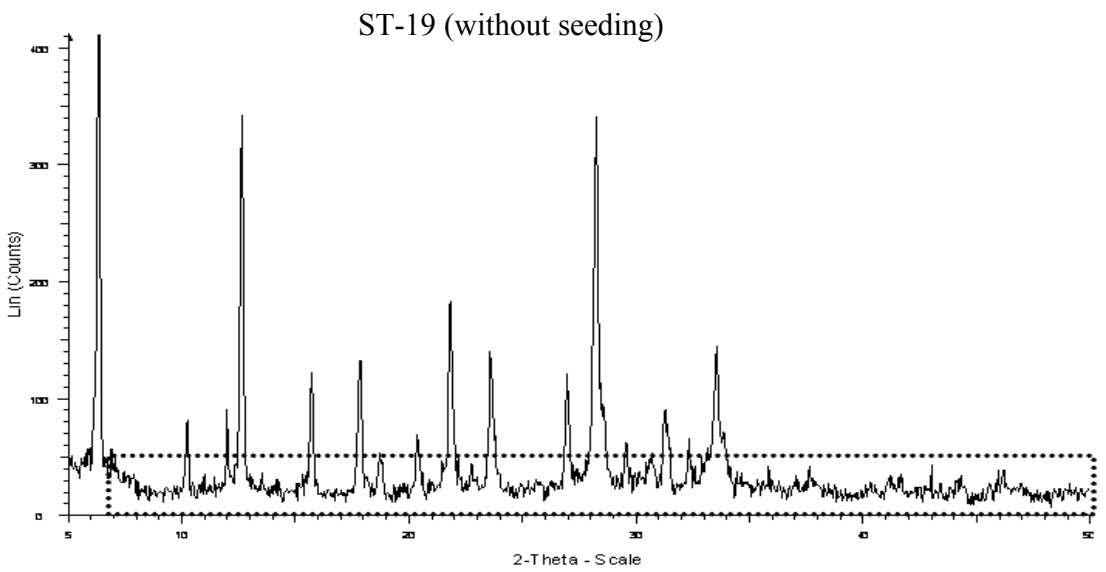

Fig. 4. XRD peak without seeding. 
presence of some amorphous material. In Fig. 5, the first XRD peak is observed at exactly $6^{0}$ and other peaks are also very sharp. It is shown to be fully crystalline. Crystallization of pure zeolite $\mathrm{Y}$ using silica is favoured at temperature lower than $100^{\circ} \mathrm{C}$, with less $\mathrm{Na}_{2} \mathrm{O}$ or greater $\mathrm{SiO}_{2}$ content in the initial mixture. This is because zeolite $\mathrm{Y}$ is highly reactive.

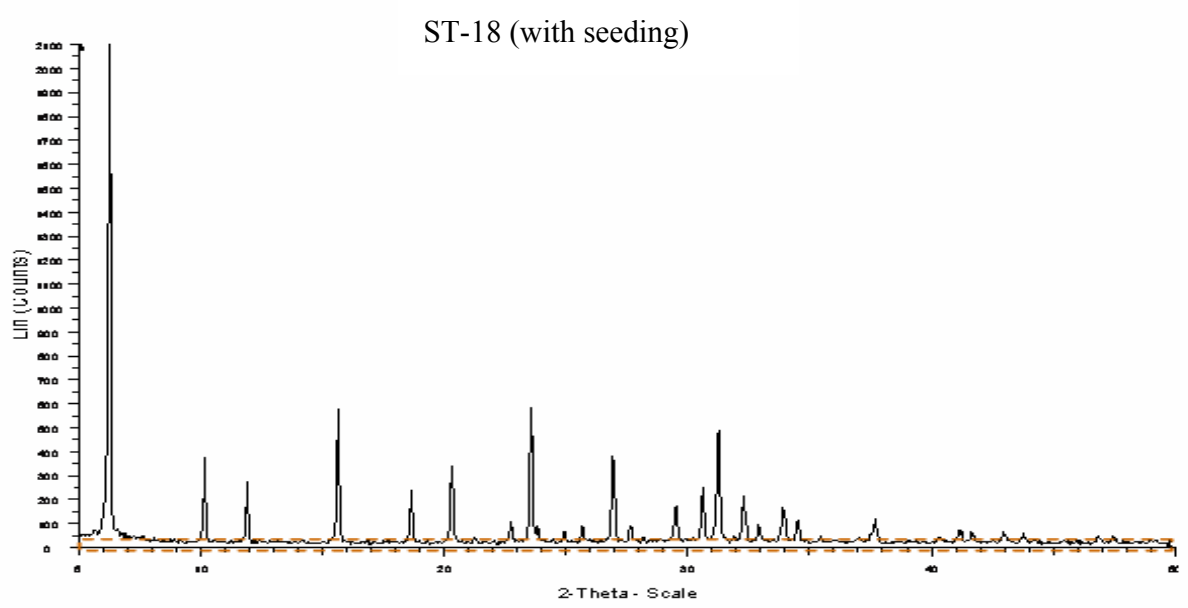

Fig. 5. XRD peak with seeding.

The synthesized zeolite $\mathrm{Y}$ gave similar scanning electron microscopy (SEM) morphology and FTIR spectrum pattern to that of the reference sample zeolite Y [7-8]. Morphologies of seeding and without seeding method are given in Figs. 6 and 7, respectively. The SEM morphology in Fig. 6 shows a very clear and sharp crystallinity, while Fig. 7 shows unclear, not crystalline with some dirt. The preparation of zeolite $\mathrm{Y}$ using the seed gel method is more accurate than the method without seeding.

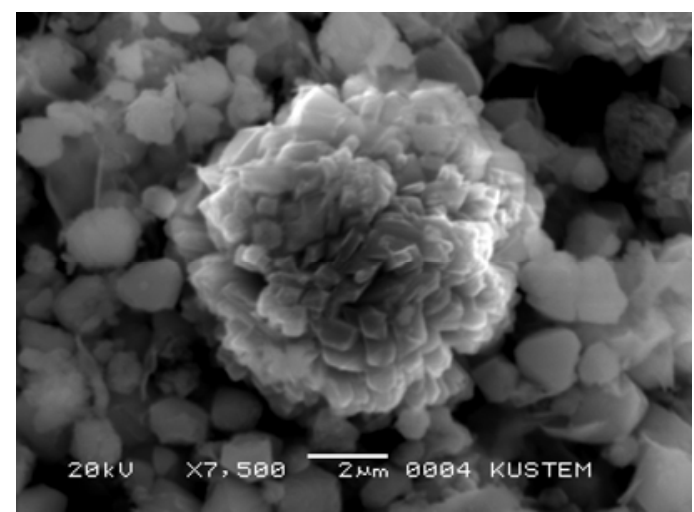

Fig. 6. SEM morphology of zeolite $\mathrm{Y}$ with seeding. 


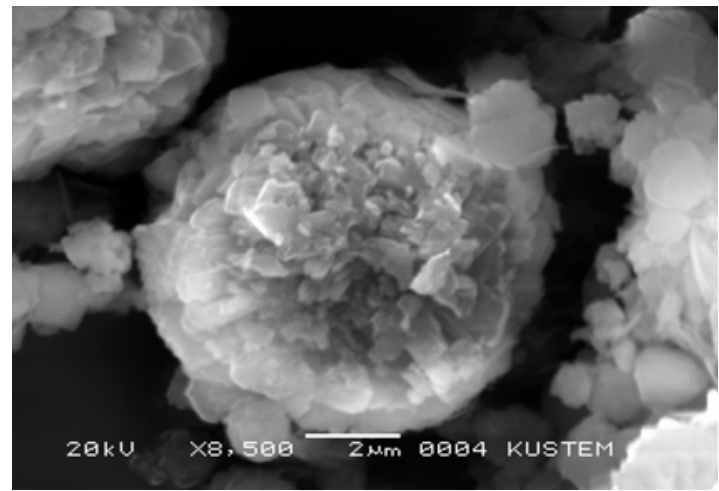

Fig. 7. SEM morphology of zeolite $\mathrm{Y}$ without seeding.

\section{Conclusion}

The preparation of amorphous RHA from rice husk through pretreatment with $10 \% \mathrm{H}_{2} \mathrm{SO}_{4}$ successfully produced a highly amorphous RHA with low impurities and better yield (95.8\%). Zeolite $\mathrm{Y}$ is available in powder form and consequently rice husk ash was suitable for synthesis of zeolite as it contains high percentage of amorphous silica form. The objective to recycle waste material to produce a valuable product and a high quality silica oxide was achieved. Preparation of zeolite $\mathrm{Y}$ with seeding yielded pure zeolite $\mathrm{Y}$ but preparation of zeolite $\mathrm{Y}$ without seeding using silica gave the mixture of zeolite $\mathrm{Y}$ and zeolite P. Meanwhile synthesis of zeolite Y using seed and feed gel method gave the maximum crystallinity and rich in zeolite $\mathrm{Y}$. Therefore in order to produce highly pure zeolite $\mathrm{Y}$ with the absence of other impurities, seeding and ageing technique must be used during the synthesis.

\section{Reference}

1. A. F. Cronstedt, Natural Zeolite and Minerals, Acad. Handl. Stockholm 17, 120 (1756).

2. D. W. Breck, Zeolite Molecular Sieves: Structure, Chemistry and Use (John Wiley, London, 1974).

3. B. Herreros, The X-Ray Diffraction Zeolite Database (1995). http://chemmacl.usc.edu/bruno/zeodat/Intro.html.

4. W. M. Meier and D. H. Olson, Atlas of Zeolite Structure Types, $3^{\text {rd }}$ Edition (Butterworths, 1992).

5. Subhash Bhatia, Zeolite Catalysis: Principles and Applications (CRC Press, Inc., Boca Raton, Florida, 1990).

6. M. M. J. Treacy and J. B. Higgins, Collection of Simulated XRD Powder Patterns for Zeolites $3^{\text {rd }}$ Edition (Elsevier, New York:, 1996).

7. B. Wang and M. Hongzhu, Micro. Meso. Materi. 25, 131 (1998). doi:10.1016/S1387-1811(98)00195-4

8. A. H. Brett, W. Hunting, J. M. Norbeck, and Y. Yan, Micro. Meso. Materi. 59, 13 (2003). doi: $10.1016 / \mathrm{S} 1387-1811(03) 00271-3$ 